Мусабеков Мурат Далибаевич

соискатель Российской академии народного хозяйства и государственной службы при Президенте Российской Федерации

\section{СОЦИОЛОГИЧЕСКИЕ ИНДИКАТОРЫ ИССЛЕДОВАНИЯ КОРРУПЦИИ И ТЕНЕВОЙ ЭКОНОМИКИ В РОССИИ}

\section{Аннотация:}

Социологические исследования являются инструментом получения объективной информации о процессах, прочсходящих в обществе, поскольку общественное мнение как отражение состояния общества выступает наиболее подвижным и восприимчивым феноменом. В статье автором исследуются особенности социологического измерения коррупции и теневой экономики для поиска инструментов снижения их уровня и механизма контроля со стороны общества. Актуальность заявленной проблемы обусловлена необходимостью усиления институтов гражданского общества в качестве партнера государственных органов в профилактике коррупции и теневой экономики. Как показывает проведенный анализ, социологический подход к исследованию коррупции и теневой экономики является востребованным в современных условиях, поскольку включает в себя изучение многообразия социальных факторов, позволяющих показать дифференцированность оценок данного феномена различными субъектами. При этом коррупция и теневая экономика как латентные социальные явления всегда с трудом поддаются социологическому измерению в силу своей скрытой природы.

\section{Ключевые слова:}

коррупция, теневая экономика, социологические опросы, социология коррупции, субъекты Российской Федерации, социологический индикатор, опрос общественного мнения, занятость.

\section{Musabekov Murat Dalibaevich}

External PhD student Russian Presidential Academy of National Economy and Public Administration

\section{SOCIOLOGICAL RESEARCH INDICATORS OF CORRUPTION AND THE SHADOW ECONOMY IN RUSSIA}

Summary:

Sociological studies are a tool for obtaining objective information on social processes due to the fact that public opinion being a reflection of the social situation is the most flexible and responsive phenomenon. The author examines the aspects of sociological indicators of corruption and the shadow economy used to find reduction tools and a monitoring mechanism applied by society. The relevance of the study is determined by the need to enhance civic institutions as a partner of public authorities in the prevention of corruption and the shadow economy. The analysis demonstrates that a sociological approach to studying corruption and the shadow economy is in demand in the modern world as it implies the examination of various social factors resulting in the fact that the constituent entities assess this phenomenon in a different way. At the same time, it is difficult to measure corruption and the shadow economy in sociological terms since they are the latent social phenomena.

Keywords: corruption, shadow economy, sociological surveys, sociology of corruption, constituent entities of the Russian Federation, sociological indicator, public opinion poll, employment.

Проблема коррупции и особенно коррумпированности государственного сектора экономики в настоящее время является одной из наиболее серьезных угроз экономической безопасности России, сдерживающей поступательное инновационное развитие, формирование реально высококонкурентного рынка и диверсификацию структуры экономики.

Как отмечает М.В. Шедий, «коррупция в современной России относится к числу наиболее острых проблем, в значительной степени препятствующих реализации социально-экономической и политической стратегии развития страны и мешающих ее эффективному развитию» [1, с. 5].

По мнению ряда исследователей, «именно отсутствие доверия в обществе... усугубляет неопределенность ситуации, а недоверие к официальным институтам порождает саму ситуацию ограниченности ресурсов и может стать причиной коррупционного выбора» [2, с. 59].

Изучение коррупции как системного социального явления начало складываться лишь в 60-х гг. XX в. в рамках социологии социального контроля и девиантного поведения. Основополагающей публикацией явилась книга С. Алатаса «Социология коррупции» 1968 г. [3], в которой автор полемизировал о влиянии коррупции на общество в целом, указывал на невозможность использования традиционных социологических методов при ее исследовании, отмечал закрытый характер данного феномена.

На наш взгляд, основная трудность социологического исследования феномена коррупции в современных условиях заключается в отсутствии в социологической науке какой-либо конкретной модели данного явления. Подобная ситуация объясняется главным образом латентным характером исследуемого явления, порождающим методологические трудности, с которыми сталкивается исследователь социальных аспектов коррупции. Существует целый ряд научных работ, 
объективно раскрывающих правовые, политические и экономические аспекты коррупционного поведения. При этом исследования, посвященные социальной природе коррупции, не имеют общей теоретико-методологической базы.

С точки зрения социологической науки методологической проблемой борьбы с коррупцией являются отсутствие системного междисциплинарного подхода к изучению проблемы, выработка рекомендаций по борьбе с данным антисоциальным явлением.

Как свидетельствуют результаты опроса фронда «Общественное мнение» в феврале 2018 г., более половины россиян считают, что искоренить коррупцию в стране невозможно. По мнению 56 \% опрошенных победить коррупцию в России в принципе нельзя. Высокий уровень коррупции в стране оценили 75 \% респондентов, о низком уровне заявили 17, еще 2 затруднились ответить [4].

В скором времени власти регионов начнут проводить социологические опросы о коррупции по методике Правительства Российской Федерации: граждан спросят, какой государственный орган они считают наиболее коррумпированным, об уровне коррупции в их регионе и о мерах по борьбе с ней [5]. По итогам исследований планируется оценить «рынок коррупции» в субъектах. Проведение подобных социологических опросов является частью «Национального плана противодействия коррупции на 2018-2020 гг.», утвержденного Президентом Российской Федерации [6].

Социологический подход к анализу коррупции и теневой экономики является продуктивным и востребованным в современных условиях, поскольку включает в себя многообразие социальных фракторов, позволяет показать дифференцированность оценок данного феномена различными субъектами. При этом коррупция и теневая экономика как латентные социальные явления всегда с трудом поддаются социологическому измерению в силу своей скрытой природы.

Социологические исследования фиксируют тесную взаимосвязь коррупции и теневой экономики. Коррупция порождает еще больший рост теневой экономики. Как отмечают эксперты Transparency International, увеличение индекса восприятия коррупции [7] на один пункт приводит к росту скрытой экономики на 7,6 \% [8, р. 23]. Данное утверждение не согласуется с концепцией теневой экономики как попытки обойти коррупцию, но согласуется с концепцией теневой экономики как порождения коррупции.

Зарубежные социологи наиболее часто рассматривают теневую экономику как социальное явление, связанное с укрытием или занижением при официальных учетах доходов от деятельности, которая не запрещена государством, либо как экономическую деятельность, ведение которой запрещается государством, в том числе в связи с тем, что она квалифицируется как преступная или как незаконно перераспределяющая созданные трудом доходы и др.

В работах известного западного ученого Ф. Шнайдера понятия «неформальная экономика» и «теневая экономика» используются в качестве синонимов [9, р. 445]. Российский исследователь Ю.П. Господарик, в свою очередь, предлагает считать теневой экономикой экономическую деятельность вне государственного контроля и учета [10, с. 96]. Как отмечают исследователи, Россия продолжает оставаться страной, где размер теневой экономики относительно ВВП страны недопустимо высок [11, с. 33].

Опросы экспертов, подтвержденные отдельными статистическими данными, показывают, что 2014-2017 гг. в России не стали временем снижения теневой экономики - напротив, в этот период доля занятых в неформальной экономике существенно увеличилась.

Согласно анализу социологических исследований и статистической информации, занятость в неформальном секторе экономики, влияющая на уровень коррупции, в разрезе регионов России может быть представлена тремя укрупненными группами: первая группа - регионы с относительно небольшой долей занятых в неформальном секторе экономике, вторая - повышенная доля такого рода теневой экономики и третья - сверхвысокий уровень занятых в неформальной экономике (см. таблицу 1).

Таблица 1 - Занятые в неформальном секторе, в \% к общей численности занятого населения в 2017 г.

\begin{tabular}{|l|c|l|c|l|c|}
\hline \multicolumn{1}{|c|}{ Группа 1 } & \multicolumn{2}{c|}{ Группа 2 } & \multicolumn{2}{c|}{ Группа 3 } \\
\hline \multicolumn{1}{|c|}{ Регион } & \% & \multicolumn{1}{c|}{ Регион } & Регион & \% \\
\hline г. Санкт-Петербург & 3,1 & Калининградская область & 23,4 & Карачаево-Черкесская Республика & 41,2 \\
\hline г. Москва & 4,9 & Тверская область & 23,6 & Кабардино-Балкарская Республика & 49,9 \\
\hline Чукотский АО & 8,1 & Нижегородская область & 30,1 & Республика Ингушетия & 51,3 \\
\hline Тюменская область & 11,6 & Воронежская область & 24,2 & Республика Дагестан & 58,1 \\
\hline Московская область & 12,3 & Белгородская область & 24,3 & Чеченская Республика & 63,4 \\
\hline
\end{tabular}

Социологические исследования показывают, что к основным социально-экономическим факторам, влияющим на усиление мотивации участия в теневой экономике, следует отнести: высокое налоговое бремя, легкость работы в неформальном секторе, сложность налоговой системы и замедление роста мировой экономики. Однако в этих условиях вполне логично, что про- 
зрачность отечественных рынков и их конкурентный потенциал будут снижаться, что, соответственно, может повлечь рост мотивации бизнеса на еще более активное участие в теневой экономике, в коррупционных процессах.

Опросы экспертов, проведенные автором, коррелируются с данными Центра социально-экономического мониторинга РАНХиГС [12], которые показывают, что в 2017 г. примерно 33 млн человек в течение года хотя бы раз получали зарплату в конверте или не были оформлены официально.

Согласно статистическим данным, за 2017 г. доля людей, занятых неофициально на дополнительной работе, выросла с 30 до 35 \%, а занятых неофициально на основной работе сократилась с 13 до 12 \% (см. рисунки 1 и 2).

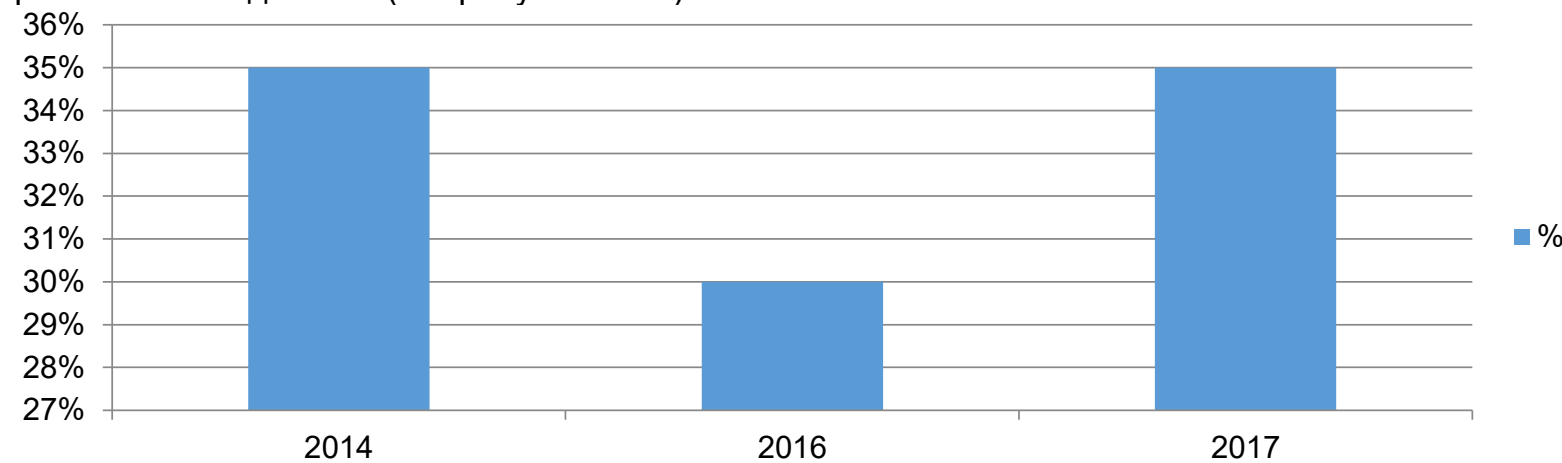

Рисунок 1 - Доля занятых неофициально на дополнительной работе

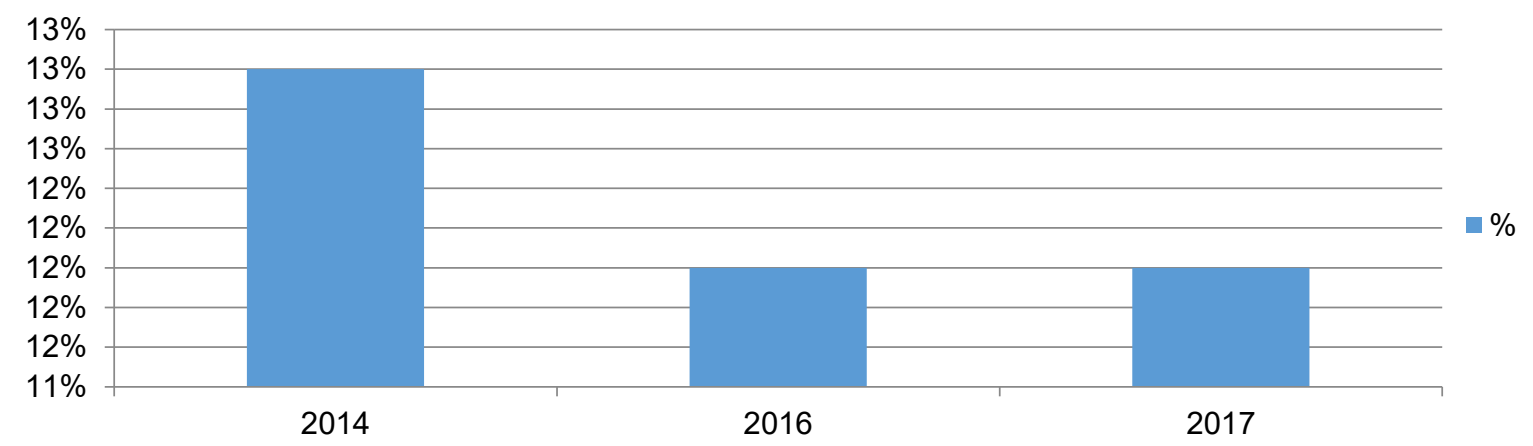

Рисунок 2 - Доля занятых неофициально на основной работе

В теневую экономику людей подталкивают низкие доходы, которые наблюдаются в последние годы, малое количество предложений официальных рабочих мест с достойной оплатой труда.

Согласно данным Центра социально-экономического мониторинга РАНХиГС [13], растет доля сотрудников, для которых не имеет значения, официальная у них работа или нет. Для значительного числа работников в первую очередь важно, «чтобы платили деньги», а не ее официальность или неофициальность. Соответственно, если в 2016 г. таких работников было 26,7 \%, то в 2017 г. их число достигло 36,8. Такие фракторы социального регулирования, как страх наказания за неуплату налогов, а также гарантии пенсионного и социального обеспечения, для таких категорий занятых оказываются вторичными.

Проведенное автором исследование показывает, что устранению теневого сектора мешает ряд объективных и субъективных причин. Среди них: недостаток денежных средств у людей, которые хотят заниматься легальным бизнесом, шантаж и давление недобросовестных чиновников, представителей преступного мира. Согласно экспертным оценкам, непродуманные действия власти порождают многочисленные причины ухода предпринимателей в тень, а вернуть их обратно оказывается не так просто.

Анализ социологического опроса, проведенного Центром социально-экономического мониторинга РАНХиГС [14], позволяет сделать вывод, что мотивы теневой экономики, связанные с проблемой выживания, наиболее сконцентрированы в моногородах, депрессивных регионах, сельских местностях, где сельское хозяйство из-за климатических условий недостаточно рентабельно. В городах-мегаполисах мотивом теневой экономики, наоборот, служит масштабное поле нерегулируемой государством экономической деятельности, возможность получать сверхприбыль, находясь в тени. Среди городов-мегаполисов масштабами своей мотивации выделяются Москва и Санкт-Петербург - в них теневой рынок по своему объему сопоставим с теневым рынком всей остальной части России.

Формирование ценностных ориентиров трудоспособного населения, связанных с деятельностью теневой экономики, во многом опосредовано социально-экономическим фоном, порождаемым экономическими санкциями зарубежных стран. 
Данные, полученные российскими социологами, подтверждают выводы итальянского социолога Доменико Де Мази, что для значительной части населения «работа становится привилегией» [15]. Однако, в отличие от экономически высокоразвитых стран, где эти изменения связаны с процессами механизации, автоматизации, роботизации производства, в России это связано со сжатием производства и рынка вакансий, падением покупательной способности населения. Под влиянием данных процессов число россиян, занятых трудом, доставляющим удовлетворение и удовольствие, в легальной экономике, сокращается.

Росту в России теневой экономики способствуют замедление движения социальных лифтов, недостаточное число мелких предпринимателей, предприятий среднего и малого бизнеса, тренд на интенсификацию труда, неоплачиваемую сверхурочную работу.

Для устранения доминирования коррупционных явлений в общественных процессах необходимо проведение эфффективной антикоррупционной политики, которая должна быть направлена не только на борьбу с последствиями коррупционных действий, но и в первую очередь на предупреждение коррупционных явлений. Необходима актуализация роли общественного мнения в формировании антикоррупционной культуры в российском обществе.

\section{Ссылки и примечания:}

1. Шедий М.В. Коррупция как социальное явление (социологический анализ) : дис. ... д-ра социол. наук. М., 2014. 393 с.

2. Макарова М.Н., Вахрушев Р.В. Коррупция как предмет социологического анализа // Вестник Удмуртского университета. Серия «Философия. Психология. Педагогика». 2012. № 3. С. 53-59.

3. Alatas S.H. The Sociology of Corruption. Singapore, 1968.

4. Опрос проводился среди граждан Российской Федерации 18 лет и старше 25 февраля 2018 г. в 104 населенных пунктах 53 субъектов РФ. В опросе приняли участие 1500 респондентов (интервью по месту жительства). Статистическая погрешность не превышает 3,6 \%. См.: Уровень коррупции в России. События в Дагестане [Электронный ресурс] // ФОМ. 2018. 13 марта. URL: https://fom.ru/Bezopasnost-i-pravo/13984 (дата обращения: 09.10.2018).

5. «Об утверждении Методики проведения социологических исследований в целях оценки уровня коррупции в субъектах Российской Федерации» [Электронный ресурс] : проект Постановления Правительства РФ (по состоянию на 06.08.2018). Доступ из информ.-правовой системы «Гарант».

6. О Национальном плане противодействия коррупции на 2018-2020 годы [Электронный ресурс] : указ Президента РФ от 29 июня 2018 г. № 37.8. Доступ из справ.-правовой системы «КонсультантПлюс».

7. Индекс восприятия коррупции - это составной индекс, основанный на данных 17 различных опросов и исследований, проведенных 13 независимыми организациями среди предпринимателей и местных аналитиков, включая опросы жителей данной страны - как ее граждан, так и иностранцев.

8. Schneider F. Shadow Economy [Электронный ресурc]. 2002. 31 p. URL: http://citeseerx.ist.psu.edu/viewdoc/download?doi=10.1.1.456.6245\&rep=rep1\&type=pdf (дата обращения: 09.10.2018).

9. Schneider F., Buehn A., Montenegro C.E. New Estimates for the Shadow Economies all over the World // International Economic Journal. 2010. Vol. 24, iss. 4: Special Issue on Shadow Economy. P. 443-461. https://doi.org/10.1080/10168737.2010.525974.

10. Господарик Ю.П. Проблема классификации видов теневой экономики в отечественной и зарубежной науке // Вестник академии. 2017. № 2. С. 96-104.

11. Антонян Т.А. В чем притягательная сила теневой экономики для субъектов малого бизнеса // Проблемы экономики и юридической практики. 2018. № 2. С. 32-35.

12. Социологический опрос занятого населения осуществлен Центром с 16 по 23 мая 2016 г. при поддержке партнерских социологических структур в субъектах РФ. Опрошено 1600 респондентов в возрасте 18 лет и старше в 35 субъектах Российской Федерации. См.: Стимулы и мотивы участия работников, занятых по найму, в официальной и некриминальной «теневой» экономической деятельности [Электронный ресурс] // Портал социологических данных РАНХиГС. URL: $\quad \mathrm{http}: / /$ social.ranepa.ru/tsentr-sotsialno-politicheskogo-monitoringa-ion/25-stimuly-i-motivy-uchastiya-rabotnikovzanyatykh-po-najmu-v-ofitsialnoj-i-nekriminalnoj-tenevoj-ekonomicheskoj-deyatelnosti (дата обращения: 09.10.2018).

13. Стимулы и мотивы участия работников ...

14. Там же.

15. Пушкарская Е. «Работа становится привилегией». Социолог Доменико Де Мази - о рынке труда в XXI в. [Электронный ресурс] // Огонек. 2018. № 15. 23 апр. URL: https://www.kommersant.ru/doc/3605257 (дата обращения: 09.10.2018).

\section{References:}

Alatas, SH 1968, The Sociology of Corruption, Singapore.

Antonyan, TA 2018, 'That Is Why the Shadow Economy Is Attractive to Small Businesses', Problemy ekonomiki $i$ yuridicheskoy praktiki, no. 2, pp. 32-35, (in Russian).

Gospodarik, YuP 2017, 'The Problem of Classifying the Types of the Shadow Economy in Russian and International Science', Vestnik akademii, no. 2, pp. 96-104, (in Russian).

Makarova, MN \& Vakhrushev, RV 2012, 'Corruption as a Subject of Sociological Analysis', Vestnik Udmurtskogo universiteta. Seriya "Filosofiya. Psikhologiya. Pedagogika", no. 3, pp. 53-59, (in Russian).

Pushkarskaya, E 2018, "Work Becomes a Privilege." Sociologist Domenico De Masi about the Labor Market in the 21st Century', Ogonek, no. 15, April 23, viewed 09 October 2018, <https://www.kommersant.ru/doc/3605257>, (in Russian).

Schneider, F 2002, Shadow Economy, 31 p. viewed 09 October 2018, <http://citeseerx.ist.psu.edu/viewdoc/download?doi=10.1.1.456.6245\&rep=rep1\&type=pdf $>$.

Schneider, F, Buehn, A \& Montenegro, CE 2010, 'New Estimates for the Shadow Economies all over the World', International Economic Journal, vol. 24, iss. 4, Special Issue on Shadow Economy, pp. 443-461. https://doi.org/10.1080/10168737.2010.525974.

Shediy, MV 2014, Corruption as a Social Phenomenon (a Sociological Analysis), PhD thesis, Moscow, 393 p., (in Russian). 